\title{
МАГИЧЕСКИЙ АТРИБУТ: МЕЖДУ ЯЗЫЧЕСТВОМ И ИСЛАМОМ
}

Целью исследования является изучение башкирских амулетов «бетеү», небольшая коллекция которых хранится в фондах Национального музея Республики Башкортостан. В музейном собрании отложились несколько типов «бетеү», бытовавших на рубеже XIX-XX вв. Предметь отличаются друг от друга формой, материалом, техникой изготовления и имеют разное содержание. Амулетам придавались магико-охранительные и сакральные свойства. Согласно древним поверьям башкир, «бетеу» приносит хозяину здоровье, долголетие, удачу во всех делах и оберегает от сглаза и влияния зловредных духов (духов болезней, шайтана и др.). Самым распространенным видом были треугольной формы амулеть, с вложенной в него молитвой или, реже, предметом. Такие кожаные амулеты-футляры носились на шнурке на шее как обереги или подиивались к одежде с внутренней стороны. Аналогичные обережные амулеты бытовали у многих народов, в том числе у среднеазиатских. Башкирские «бетеү» как магический предмет имели широкое распространение в прошлом и все еще популярны в настоящчее время среди населения, прежде всего, пожилого возраста. Поэтому они представляют собой важный этнографический источник для изучения духовной и материальной культуры башкирского народа.

Ключевые слова: башкирский амулет, оберег, Наџиональный музей Республики Башкортостан, башкиры, музейный предмет, экспонат, магическая сила

Ссылка при цитировании: Сулейманова М.Н., Нигматуллина З.Ф. Магический атрибут: между язычеством и исламом // Вестник антропологии, 2021. № 3. С. 191-198.

У всех народов во все времена широко использовались различные обереги и амулеты. Их наделяли магической и таинственной мощью, способной уберечь человека от влияния злых сил. Как правило, их носили на теле или на одежде. Согласно народным верованиям, например, башкир, амулеты, специально изготовленные из какого-либо материала, или части тела (когти, зубы), кости животных и птиц обладали сверхъестественной силой, а значит, были способны защитить от «дурного глаза», болезней и даже от смерти. Само слово «амулет» производят от латинского «amoliri», что значит «отражение чар», а с арабского «hamala» - «носить» (Энцикло-

Сулейманова Маргарита Нугмановна - к.и.н., доцент кафедры истории Республики Башкортостан, археологии и этнологии, Институт истории и государственного управления Башкирского государственного университета (450076 г. Уфа, ул. Заки Валиди, 32). Эл. почта: suleymanie@mail.ru

Нигматуллина Зиля Фасимовна - главный хранитель музейных предметов ГБУ РИКМЗ «Древняя Уфа», аспирант, Институт истории и государственного управления Башкирского государственного университета (450076 г. Уфа, ул. Заки Валиди, 32). Эл. почта: zilek77@rambler.ru 
педический словарь 1890: 678). Впервые амулет упоминается у Плиния Старшего древнеримского писателя, автора «Естественной истории», который жил в I в. н.э. И под ним он подразумевал средство против яда (Там же: 678).

В «Атеистическом словаре» амулет - это предмет, обладающий сверхъестественной силой, способной охранять его владельца от несчастий, болезней и «злых чар». Считается, что вера в амулет восходит к первобытному фетишизму и магии, и сохраняется в современных религиях (кресты, ладанки в христианстве) и в так называемых бытовых суевериях (Атеистический словарь 1985: 16). С древнейших времен амулеты - «бетеү» были известны и у башкир. Само название исследователи производят от древнетюркского «битиг», что означает «письмо», «надпись» (Бетеу 2020). В башкирско-русском словаре этнокультуроведческой лексики башкирское «бетеү» (бөтөй) определен как амулет, или как «молитвенник в виде треугольника, обшитый тканью» (Багаутдинова 2012: 37).

Происхождение «бетеү» связано с доисламскими представлениями башкир. Им приписывали чудодейственную силу, способную уберечь владельца от сглаза и от злых духов и носили на шее, либо подвешивали к одежде с внутренней стороны. Особенно широко они использовали их с целью оберечь новорожденных, детей и женщин. Например, в прошлом у башкир повсеместно был распространен обычай вешать амулеты по четырем углам колыбели, сохранявшийся у них вплоть до настоящего времени (Хисамитдинова 2010: 59).

Работ, посвященных различным типам (нательных, нашивных) башкирских амулетов нет. Тем не менее, упоминания о них в трудах исследователей неоднократны, чаще всего, в работах, посвященных исследованию методов народной медицины. В них амулеты рассматриваются как один из основных способов лечения болезней. Нередки также упоминания об амулетах в исследованиях о женской одежде башкир, в которых отмечается о наделении магическими оберегательными свойствами элементов украшений традиционного костюма.

Выдающийся этнограф, автор научных работ по этнографии и традиционным верованиям башкир С.И. Руденко, рассматривая способы лечения у башкир, отмечал, что «для предохранения, а также для избавления от болезни уральские башкиры вместе с изречениями из Корана вешали на шею больных (особенно детей) амулеты (бетеу), медвежьи когти (aüыу тырнагы) и клыки (aйыу теше), так как болезнь, боясь их, как самого медведя, оставляла больного». В качестве примера Сергей Иванович приводит амулет башкирского рода катай, который состоит из четырех треугольных кожаных мешочков нашитых на кожаную ленту (Руденко 2006: 274-275).

При изучении девичьего затылочного украшения елкәмес или елкәлек, существовавшего в южном и восточном районах Башкортостана, этнограф С.Н. Шитова обратила внимание на сведения из статьи итальянского ученого Стефано Соммье, побывавшего в конце XIX в. в башкирской деревне Ташбулатово Оренбургской губернии ${ }^{1}$. С. Соммье писал, что видел на девочке расшитый бисером и металлическими украшениями кожаный треугольник между косами. Подобные треугольные узоры на мужских и на повседневных женских сарыках (обуви, с головкой из домашней выделки грубой кожи и длинным суконным вышитым голенищем), безусловно, можно отнести к амулетам бетеү (Шитова 1995: 119, 147).

${ }^{1}$ В настоящее время дер. Ташбулатово на территории Абзелиловского района Республики Башкортостан. 
В фондах Национального музея Республики Башкортостан хранится всего пять экземпляров амулетов ${ }^{1}$. Об этих экспонатах сохранилась минимальная информация. Они записаны в Книгу поступлений музея в 1950 г. как башкирские «бетеү» - амулеты, но без указания места и времени приобретения. Учитывая, что именно в 50-х гг. $\mathrm{XX}$ в. в музее массово начали записывать предметы, которые накопились в фондах в результате собирательской деятельности в 20-30-х гг. ХХ в., можно предположить, что периодом изготовления и бытования данных амулетов является конец XIX - начало XX вв. Рассматриваемые амулеты являются шейными, поясными, а также предусмотренными для нашивки на одежду или ношения с собой. Все они являются персональными, то есть когда-то принадлежавшими конкретному лицу, и ручного изготовления. Фабричного или массового кустарного изготовления амулетов у башкир не существовало. Сохранившиеся в фонде бетеү по форме треугольные и прямоугольные. Средний их размер составляет 3,5х6 см. Башкирские амулеты представляют собой тканевый или кожаный футляр, сшитый внутренним ручным швом, в котором содержится тот или иной предмет (бумажный листок, кости, засушенные травы и т.д.).

Нательные бетеу, чаще всего имеющие форму треугольника, не изнашивались именно благодаря своеобразной кожаной или тканевой оболочке. В треугольник вкладывали бумажку, на которой были написаны молитвы из Корана. Чаще всего, на бумажке писали небольшой отрывок из наиболее популярных и известных в народе мусульманских молитв, например, суру из Корана «аль-Фатиха». В амулетах из коллекции Национального музея РБ также содержатся записанные молитвы (НМ РБ ОФ 8338). Содержание письменных вкладышей в

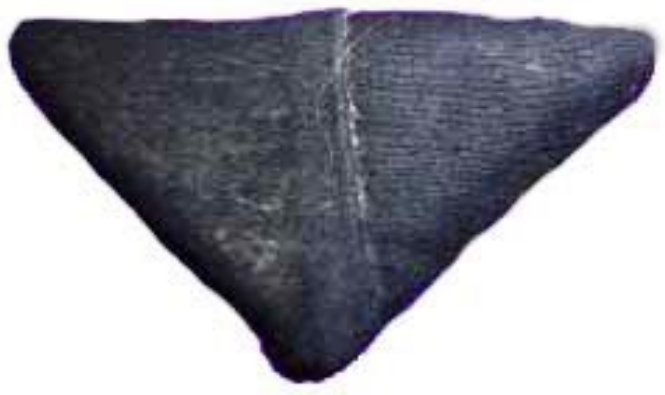

Рис. 1. Бетеу. Башкирский амулет. Национальный музей Республики Башкортостан. НМ РБ ОФ 8338. Фото 3.Ф. Нигматуллиной. башкирских бетеу, на наш взгляд, представляет определенный интерес. Полностью раскрыть сложенный листочек в амулет для прочтения возможно только при организации музеем реставрационных мероприятий в отношении данных экспонатов. Отметим, что обычай вкладывания листочка с молитвой в защитных целях в амулеты было принято не только у многих тюркских народов, в том числе и у башкир, но и у монголоязычных народов. Например, у уйгуров бумажный листочек-вкладыш содержал буддийские молитвы, к которому добавляли целебные травы и лоскутки материи (Чвырь 1986: 231).

Самым распространенным бетеу среди башкир являлся один треугольный амулет, но имелись и другие, с гораздо большим количеством. В Национальным музее хранится бетеу в виде тесьмы, с подшитыми к ней шестью треугольными и одним прямоугольным мешочками, предназначенный для ношения на шее. Длина тесьмы равна 82 см, а в мешочки также вложены бумажные листочки с мусульманскими молитвами (НМ РБ ОФ 3605). Треугольная форма бетеY - наиболее распространенная форма оберегов, способных по народным поверьям защитить от дурного глаза, злых духов, болезней.

${ }^{1}$ Национальный музей Республики Башкортостан (далее - Национальный музей РБ). 
Треугольные обереги бытовали у многих народов, например, у среднеазиатских казахов, узбеков, таджиков, каракалпаков, уйгуров и туркмен. У них широко были распространены треугольные амулетницы, с вложенными в них предметами или молитвами. Наиболее часто встречались металлические амулетницы - неповторимые образцы ювелирного искусства народов Средней Азии, которые служили и оберегом и одновременно украшением. Среди казахских амулетов также имеется треугольный нашейный амулет «туморша», являющийся одним из основных форм такого рода талисмана. Узбекские и таджикские нашейные амулеты «буйинтумор» одновременно выполняли функцию оберега и украшения. Схожие украшения «бытовали также на Ближнем Востоке, в Египте. Такого рода амулеты среднеазиатского производства были обнаружены также на Руси, в Прибалтике и даже Норвегии» (Гюль 2008).

Арабские амулеты тоже имели схожую форму, содержание и функции как башкирские. Они были в виде маленьких кожаных сумок, куда вшивали бумагу с написанной сурой из Корана или рисовали магический знак (Амулет 2020).

Вообще, треугольная форма достаточно распространенная в традиционном творчестве башкир. Например, в ковроткачестве, в вышивке узор в форме треугольника широко представлен. Интересно самоназвание узора, звучащего как «бетеусә», и который, несомненно, произошел от слова «бетеү». Подобный узор можно встретить на старинных полотенцах, занавесках, коврах и других предметах быта. Согласно верованиям башкир, такой узор обладал обережной силой. Более того, форму сакрального узора придавали традиционной выпечке, например, обрядовому печенью, предназначенному для свадебных торжеств (бетеусә), с целью уберечь семью и близких от нечистой силы или сглаза (Хисамитдинова 2010: 60).

Другим примером сакральности этого узора или формы являются обережные рубашки для новорожденного - «бетеу күлдәк» и одеяла-обереги из треугольных лоскутков - «бетеү юрган». Такую рубашку шила повитуха из треугольных лоскутков, а обережное одеяло шили семье, где умирали дети (Багаутдинова 2012: 37).

Если брать более отдаленные примеры, то следует упомянуть, что в орнаментике керамических сосудов различных археологических культур представлен этот узор. Так, орнаментирование сосудов вокруг тулова цепью из треугольников встречается во многих археологических культурах эпохи бронзы на территории Европы. Или узоры на сосудах катакомбной культуры Юга России (Голан 1993: 84). На территории Южного Урала этот узор в орнаментации сосудов использовали племена эпохи бронзы. В синташтинской культуре сосуды орнаментировались треугольниками по плечу, а сосуды алакульской, дополнялись косыми треугольниками. Орнамент в виде треугольника перед обжигом на сосуд наносили и представители срубной культуры (Кульшарипов Т.1. 2009: 93, 103, 117, 144).

В фондах Национального музея, помимо треугольных, имеются и другие типы амулетов. И они отличаются друг от друга, как по содержанию, так и по виду. Одним из них является амулет, представляющий собой мешочек из серого ситца на синем шнурке. В него вложена бумажка с написанной на ней арабской вязью молитвой из Корана. Размер мешочка равен 6х6,5 см. (НМ РБ ОФ 3493). В отличие от других бетеу он является четырехугольным. Такие экземпляры бетеү предназначались для ношения в кармане или их нашивали на одежду. Но если исходить из практичности и удобства, то встречались случаи, когда прямоугольный амулет носили на шнурке через плечо по диагонали под мышкой. Например, такой способ ношения прямоугольного подмы- 
шечного амулета «колтыкща » есть у казахов (Гюль 2008).

Следующий амулет из музейных фондов является нательным и предназначается для ношения на шее. От других он отличается, прежде всего, своим содержимым. Он представляет собой пять мешочков, подвешенных на красный шнурок. Причем содержимое мешочков различно. Так, в первый прямоугольный мешочек из лилового бархата вложена завернутая в вату кость кошки. Второй треугольный мешочек из красного бархата плотно зашит и поэтому рассмотреть содержимое не представляется возможным. Но в Книге поступлений в описании данного музейного предмета дана следующая запись: «части пленки от новорожденного ребенка». В третий мешочек прямоугольной формы, тоже сшитого из бархата, вложены семена, которые в учетной документации музея записаны как «черное зерно (кара-зет орлого)». В четвертый мешочек прямоугольный формы зашиты написанная на клочке бумаги мусульманская молитва и черное зерно. Определить, какая конкретно записана молитва и зернышко, какого растения, выяснить точно, к сожалению, пока не получается. Это можно будет сделать при полной реставрации предмета, когда после распаривания швов мешочка представиться возможность изучить его содержимое. Пятый прямоугольной мешочек из голубого шелка, содержит мелко накрошенные кусочки засушенных листьев и трав (НМ РБ ОФ 3494). Как видим, все содержимое его состоит из различных предметов, которые, по-видимому, наделяли особыми чудодейственными свойствами. Так, содержимое лилового мешочка - кошачья кость по поверьям башкир обладала магическими свойствами, а сама кошка являлась символом достатка, счастья и благополучия. Считалось, что кошка «непримиримый враг нечистых сил, охранительница людей, прежде всего детей, от происков злокозненных духов» (Илимбетова, Илимбетов

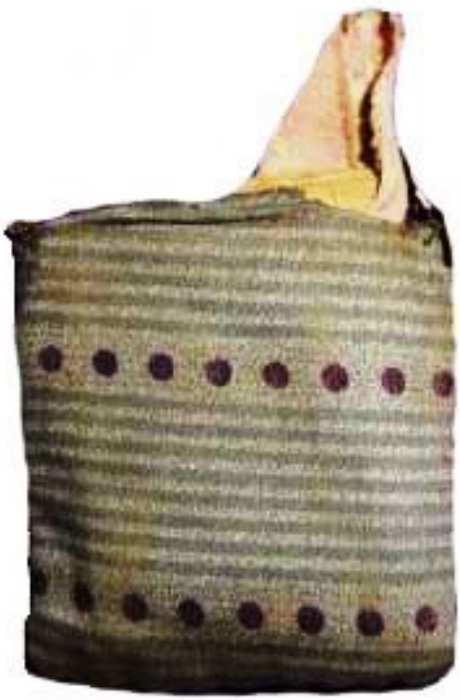

Рис. 2. Бетеу. Башкирский амулет. Национальный музей Республики Башкортостан. НМ РБ ОФ 3493. Фото З.Ф. Нигматуллиной.

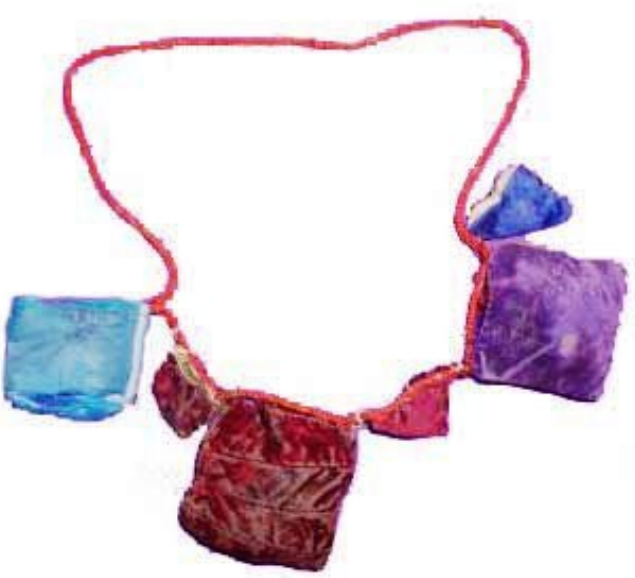

Рис. 3. Бетеу. Башкирский амулет. Национальный музей Республики Башкортостан. НМ РБ ОФ 3494. Фото З.Ф. Нигматуллиной. 
2012: 262). Башкиры издревле использовали кости животных в магических целях, например, вешали кости различных животных (медведя, волка, рыси) к колыбели, чтобы защитить ребенка от нечистой силы (Сулейманова 2005: 67). Или для защиты младенцев от болезней и сглаза использовали медвежий коготь (aйыу тырнаzы) (Багаутдинова 2012: 17).

Плаценте (бала яткылығы) башкиры придавали особые сакральные свойства. Например, с ее помощью стремились повлиять на будущее ребенка (Хисамитдинова 2010: 57). Другие предметы из амулета - черное зерно, определенные травы и листики, несомненно, неслучайный набор и должны были оказывать магическое воздействие на обладателя данного амулета. Той же цели служила и записанная на клочке бумаги мусульманская молитва, причем вложенная в мешочек вместе с черным зернышком. Такой амулет, согласно поверьям, имел сильные защитные и лечебные свойства. Очевидно, что данный экземпляр башкирского бетеү относится к числу древних по происхождению амулетов, в котором уникальным образом соединились черты языческих и мусульманских верований и является ярким примером религиозного синкретизма.

У башкир имелись и другие разновидности бетеу. Одними из них являются редкие поясные. В Национальном музее на хранении имеется единственный экземпляр поясного бетеү. Это узкий поясок серебряного позумента, который нашит на тканевую ленту и застегивается сзади (НМ РБ ОФ 3502). На ленту по центру между двумя каплевидными бирюзовыми кулонами нашита сердоликовая круглая пуговица. Также на ленту нашиты висячие круглые красные бусины и раковины каури. Длина составляет 62,5 см. Сердолик (кыззыл акык) для башкир имел отгонную, охранительную и лечебную силу. Так в защитных целях молодым невесткам старшие советовали носить перстень и браслет с сердоликом. Кроме того, считалось, что сердолик лечит болезни сердца. Раковинам каури башкиры приписывали сакральные свойства, которыми щедро украшали женские головные уборы. Было принято дарить молодой невесте раковины ужовки с пожеланиями плодовитости (Хисамитдинова 2010: 20, $154,189,201,219)$. Как видим, ни одна деталь данного амулета не была случайной.

Необходимо отметить, что редкие и оригинальные экземпляры башкирских амулетов, сохранившиеся в фондах Национального музея РБ, являются свидетельством древних представлений башкир (верования, связанные с почитанием животного мира, культа предков, загробной жизни и т.д.), в которых удивительным образом переплелись доисламские верования с мусульманской религией. К сожалению, в музейных фондах сохранились всего лишь пять экземпляров башкирских амулетов бетеу, происхождение которых, судя по их деталям, относится к рубежу XIX-XX вв. Малочисленность этих предметов в коллекциях музея можно связать, видимо, с атеистическим периодом в истории страны, когда какие-либо проявления религиозности населения жестко пресекались. Поэтому сам факт сохранения амулетов уникален.

Таким образом, рассмотренные в данной статье башкирские бетеу представляют собой уникальный этнографический источник, происхождение которого связано с архаичными пластами традиционного религиозного сознания. Несомненно, башкирские амулеты бетеу должны стать предметом более глубокого научного исследования.

\section{Источники и материалы}

НМ РБ ОФ 8338 - Национальный музей Республики Башкортостан основной фонд 8338. НМ РБ ОФ 3605 - Национальный музей Республики Башкортостан основной фонд 3605. 
НМ РБ ОФ 3493 - Национальный музей Республики Башкортостан основной фонд 3493.

НМ РБ ОФ 3494 - Национальный музей Республики Башкортостан основной фонд 3494.

НМ РБ ОФ 3502 - Национальный музей Республики Башкортостан основной фонд 3502.

Амулет. Википедия. Свободная энциклопедия. https://ru.wikipedia.org/wiki (дата обращения: 10.12.2020)

Бетеу. Википедия. Свободная энциклопедия. https://ru.wikipedia.org/wiki/\%D0\%91\%D0\%B5 $\% \mathrm{D} 1 \% 82 \% \mathrm{D} 0 \% \mathrm{~B} 5 \% \mathrm{D} 1 \% 83$ (дата обращения: 10.12.2020).

\section{Научная литература}

Абдусамедов А. И., Алейник Р. М., Алиева Б. А. и др. (сост.) Атеистический словарь // под общ. ред. М. П. Новикова. 2-е изд., испр. и доп. М.: Политиздат, 1985. http://religion.niv.ru/doc/ dictionary/atheistic/fc/slovar-192-2.htm\#zag-85 (дата обращения: 10.12.2020)

Андреевский И.Е. (под ред.) Энциклопедический словарь. СПб: Ф.А. Брокгауз, И.А. Ефрон, 1890. 950 c. https://dlib.rsl.ru/viewer/01003924258\#?page=210 (дата обращения: 10.12.2020)

Багаутдинова М.И. Башкирско-русский словарь этнокультуроведческой лексики. Уфа: Китап, 2012. $148 \mathrm{c}$.

Голан А. Миф и символ. Москва: Русслит, 1993. 375 с.: с ил.

Гюль Э. К вопросу о генезисе амулетниц-тумаров. Евразийский исторический сервер. 2008. https://kyrgyz.ru/articles/library/elmira_gyul_k_voprosu_o_genezise_amuletnits-tumarov/ (дата обращения: 10.12.2020)

Илимбетова А.Ф., Илимбетов Ф.Ф. Культ животных в мифоритуальной традиции башкир. Уфа: АН РБ, Гилем, 2012. 704 с.

Кульшарипов М.М. (гл. ред.) История башкирского народа. В 7 т. М.: Наука, 2009. Т.1. 400 с. Руденко С.И. Башкиры. Историко-этнографические очерки. Уфа: Китап, 2006. 376 с.

Сулейманова М.Н. Доисламские верования и обряды башкир: монография. Уфа: РИО БашГУ, 2005. $146 \mathrm{c}$.

Хисамитдинова Ф.Г. Мифологический словарь башкирского языка. М.: Наука, 2010. 452 с.

Чвырь Л.А. Сравнительный очерк традиционных украшений уйгуров и соседних народов Средней Азии (XIX - начало XXв.). Восточный Туркестан и Средняя Азия в системе культур древнего и средневекового Востока / под ред. Б.А. Литвинского. М., 1986. С. 211-250. Шитова С.Н. Башкирская народная одежда. Уфа: Китап, 1995. 237 с.: с ил.

Suleymanova, Margarita N., Nigmatullina, Zilya F.

\section{Magic Attribute: Between Paganism and Islam}

DOI: $10.33876 / 2311-0546 / 2021-3 / 191-198$

The research aims to study the Bashkir amulets "beteu", a small collection of which is kept in the funds of the National Museum of the Republic of Bashkortostan. The collection possesses several types of "beteu", used at the turn of the 19th-20th centuries. Objects differ from each other in shape, material, manufacturing technique, and usage. Magical, protective and sacred properties were attributed to the amulets. The Bashkirs believed that "beteu" brought health, longevity, good luck, and protection from the harmful influence of otherworldly forces. Triangular amulets were the most common, with a prayer or, less often, an object embedded in it. Such leather amulets were worn on a cord around the neck or were sewn to clothes from the inside. Many Central Asian peoples used similar amulets. The Bashkir "beteu", a magical object of cult and ritual significance, combines the pre-Islamic beliefs and the Muslim religion. Therefore, they represent an important ethnographic source for studying the spiritual and material culture of the Bashkir people. 
Keywords: Bashkir amulet, amulet, National Museum of the Republic of Bashkortostan, Bashkirs, museum item, exhibit, magical power

For Citation: Suleymanova, M.N., Nigmatullina Z.F. 2021. Magic Attribute: Between Paganism and Islam. Herald of Anthropology (Vestnik Antropologii) 3: 191-198.

Author Info: Suleymanova, Margarita Nugmanovna - PhD in Historical sciences, Associate Professor, Institute of History and State Administration, Bashkir State University (Ufa, RF). E-mail: suleymanie@mail.ru

Nigmatullina Zilya Fasimovna - Museum keeper, Republican Historical and Cultural Museum-Reserve «Ancient Ufa», Postgraduate student, Institute of History and State Administration, Bashkir State University (Ufa, RF). E-mail: zilek77@rambler.ru

\section{References}

Abdusamedov, A.I., R.M. Aleinik, and B.A. Alieva, (ed.). 1985. Ateisticheskii slovar' [Atheistic dictionary]. 2 vols. Moscow: Politizdat. http://religion.niv.ru/doc/dictionary/atheistic/fc/ slovar-192-2.htm\#zag-85

Andreevsky I.E. (ed.). 1890. Entsiklopedicheskii slovar' [Encyclopedic dictionary]. St. Petersburg: F.A. Brokgauz, I.A. Efron. https://dlib.rsl.ru/viewer/01003924258\#?page=210 (data obrashcheniia: 10.12 .2020$)$

Bagautdinova M.I. 2012. Bashkirsko-russkii slovar' etnokul'turovedcheskoi leksiki [Bashkir-Russian dictionary of ethnocultural vocabulary]. Ufa: Kitap.

Chvyr L.A. (ed.). 1986. Sravnitel'nyi ocherk traditsionnykh ukrashenii uigurov i sosednikh narodov Srednei Azii (XIX - nachalo XX v.). Vostochnyi Turkestan i Sredniaia Aziia v sisteme kul'tur drevnego i srednevekovogo Vostoka [East Turkestan and Central Asia in the system of cultures of the ancient and medieval East], 211-250. Moscow.

Golan A. Mif i simvol [Myth and symbol]. Moscow: Russlit.

Giul' E. K voprosu o genezise amuletnits-tumarov [To the question of the genesis of amulets-tumars]. https://kyrgyz.ru/articles/library/elmira_gyul_k_voprosu_o_genezise_amuletnits-tumarov/.

Ilimbetova, A.F., Ilimbetov F.F. 2012. Kul't zhivotnyh v miforitual'noj tradicii bashkir. [The cult of animals in the mythological tradition of the Bashkirs]. Ufa: AN RB, Gilem.

Kul'sharipov M.M. 2009. (ed.) Istoriia bashkirskogo naroda [History of the Bashkir people]. 7 vols. Moscow: Nauka, Vol. 1.

Rudenko S.I. 2006. Bashkiry. Istoriko-etnograficheskie ocherki [Bashkirs. Historical and ethnographic essays]. Ufa: Kitap. 376 p.

Suleimanova M.N. 2005. Doislamskie verovaniia i obriady bashkir: monografiia [Pre-Islamic Beliefs and Rites of the Bashkirs: Monograph]. Ufa: RIO BashGU.

Khisamitdinova F.G. 2010. Mifologicheskii slovar'bashkirskogo iazyka [Mythological dictionary of the Bashkir language]. Moscow: Nauka.

Shitova S.N. 1995. Bashkirskaia narodnaia odezhda [Bashkir folk clothes]. Ufa: Kitap. 